\title{
Addition of hyaluronidase to lignocaine with adrenaline for retrobulbar anaesthesia in the surgery of senile cataract
}

\author{
IAN THOMSON \\ From Norton Eye Unit, Norton, Zimbabwe
}

SUMmARY A double-blind trial demonstrates the effectiveness of adding hyaluronidase to lignocaine with adrenaline in producing ocular akinesia and anaesthesia in retrobulbar nerve blocks. $92 \%$ of the blocks in which hyaluronidase was used for intracapsular cataract surgery were judged successful compared with $56 \%$ of those without added hyaluronidase $(\mathrm{p}<0 \cdot 01)$.

Hyaluronidase is an enzyme which depolymerises the polysaccharide hyaluronic acid present in the intracellular matrix of connective tissue.' It increases the spread of locally injected anaesthetics and so should improve the effectiveness of nerve blocks.

Reports on its value in retrobulbar anaesthesia have differed. Atkinson ${ }^{2}$ and Lebensohn ${ }^{3}$ found it to be useful, while Mindel ${ }^{4}$ did not find it to be effective. Dissatisfaction with the initial success rate of lignocaine with adrenaline alone prompted this trial with the addition of hyaluronidase to the anaesthetic.

\section{Materials and method}

One hundred and fifty consecutive patients admitted for senile cataract surgery were randomly allocated to one of two groups, A or B. Two identical $150 \mathrm{ml}$ bottles of local anaesthetic were prepared. To each bottle was added $100 \mathrm{ml}$ of $2 \%$ lignocaine and $1 \mathrm{ml}$ of adrenaline $1 / 1000$. To one of the bottles 1500 IU of hyaluronidase was added. One bottle therefore contained $100 \mathrm{ml}$ of $2 \%$ lignocaine with adrenaline $1 / 100000$ and other $100 \mathrm{ml} 2 \%$ lignocaine with adrenaline $1 / 100000$ and $15 \mathrm{IU}$ hyaluronidase $/ \mathrm{ml}$.

The bottles were labelled A and B by an independent observer who was told which bottle contained the hyaluronidase. After the labelling of the bottles only the observer knew what was in each bottle. The same procedure was repeated when more anaesthetic was needed. The code was broken at the end of the series of 150 patients.

Correspondence to Dr I M Thomson, Agogo Hospital, PO Box 27, Agogo, Ghana.
Since no trouble had been previously experienced with facial nerve blocks, only $2 \%$ lignocaine with adrenaline $1 / 100000$ (prepared separately) was usedo for this procedure. A combined van Lint and O'Brien technique is used routinely, with $1 \mathrm{ml}$ injected over the mandible $2.5 \mathrm{~cm}$ in front of the ear lobe and $2.5 \mathrm{ml}$ injected above and below the orbital rim, the injection being started $2.5 \mathrm{~cm}$ lateral to the orbital rim.

The retrobulbar injection was $2 \mathrm{ml}$ given through a $26 \mathrm{G} 50 \mathrm{~mm}$ needle. The injection was started at the lower, lateral orbital margin, the needle passed straight back through the skin of the lower lid for $1 \mathrm{~cm}$ to go through the orbital septum, and then angled at $45^{\circ}$ to follow the lateral wall of the orbit to the apex. An attempt was made to place the anaesthetic solution within the muscle cone.

Preoperative sedation was $25 \mathrm{mg}$ chlorpromazine given orally approximately half an hour before surgery. No local anaesthetic drops were put in the eye either before or during the operation.

Six patients were operated on at each session. All anaesthetics were given by me at the start of each session and before scrubbing up for surgery. The first patient to be operated on therefore had his local anaesthetic about 15 minutes before surgery (10 minutes to give six anaesthetics plus 5 minutes for scrubbing up) and the last patient about one hour and five minutes after the local anaesthetic, an average of 10 minutes being allowed for each operation. This time gap is well within the normal range given for the duration of lignocaine with adrenaline. ${ }^{5}$ The addition of hyaluronidase has been shown not to reduce this duration. ${ }^{6}$ 
The patients were operated on in the order in which they presented at the outpatients department and were given anaesthetic A or B alternately. No attempt was made to time the onset of akinesia or anaesthesia. Akinesia and anaesthesia were assessed on the operating table by me immediately before surgery and after the eye had been washed and draped: The following grading system was used:

Grade 1. Complete akinesia and anaesthesia as shown by $(a)$ painless insertion of the upper lid suture; $(b)$ Complete absence of eye movements; (c) the eye in the primary position; $(d)$ complete anaesthesia of conjunctiva and cornea.

Grade 2. Akinesia and anaesthesia considered adequate for safe intraocular surgery as shown by $(a)$ painless insertion of upper lid suture; $(b)$ eye movements less than $15^{\circ}$ (estimated) in any direction of gaze; (c) complete anaesthesia of conjunctiva and cornea.

Grade 3. Unsuccessful akinesia and anaesthesia as judged by (a) painful insertion of the upper lid suture; (b) eye movements greater than $15^{\circ}$ (estimated) in any direction of gaze.

Patients with a grade 3 anaesthetic had a repeat retrobulbar injection of $2 \%$ lignocaine with adrenaline $1 / 100000$.

The surgical procedure consisted of (1) a $3 / 0$ silk suture passed through the central upper lid margin and clipped with mosquito forceps to retract the lid; (2) a Graefe knife section; (3) a peripheral iridectomy; (4) one preplaced $8 / 0$ silk suture; (5) intracapsular cryoextraction of the lens; (6) two further $8 / 0$ corneoscleral sutures. A superior rectus suture for eye fixation was not used.

Three patients had a retrobulbar haemorrhage and were excluded from that particular session but reentered the trial with the same anaesthetic when they were rescheduled for surgery one week later. All preoperative tensions were less than $21 \mathrm{mmHg}$ Schiøtz.

\section{Results}

The results were analysed by $\chi^{2}$ test with one degree of freedom.

A successful anaesthetic was grade 1 or grade 2 . Of the 150 blocks $74 \%$ were successful first time, with the remainder needing a second retrobulbar injection. Of the 75 who had added hyaluronidase $92 \%$ were successful compared with only $56 \%$ of those without hyaluronidase $(\mathrm{p}<0 \cdot 01)$ (Table 1$)$.

Sixty-seven of the 150 anaesthetics were grade 1 and nearly three-quarters of them had added hyaluronidase. Conversely nearly $80 \%$ of the 39 anaesthetic failures were in patients without added hyaluronidase $(p<0 \cdot 01)$. The 44 grade 2 anaesthetics
Table 1 Success and failure rate of anaesthesia in all patients and in those with added hyaluronidase and those without

\begin{tabular}{lccr}
\hline & Success $(\%)$ & Failure (\%) & Total $(\%)$ \\
\hline All anaesthetics & $111(74)$ & $39(26)$ & $150(100)$ \\
With hyaluronidase & $69(92)$ & $6(8)$ & $75(100)$ \\
Without hyaluronidase & $42(56)$ & $33(44)$ & $75(100)$ \\
\hline
\end{tabular}

Table 2 Grade of anaesthesia achieved in patients with added hyaluronidase and without hyaluronidase

\begin{tabular}{lllr}
\hline $\begin{array}{l}\text { Grade of } \\
\text { anaesthesia }\end{array}$ & $\begin{array}{l}\text { With }(\%) \\
\text { hyaluronidase }\end{array}$ & $\begin{array}{l}\text { Without }(\%) \\
\text { hyaluronidase }\end{array}$ & Total(\%) \\
\hline 1 & $48(72)$ & $19(28)$ & $67(100)$ \\
2 & $21(48)$ & $23(52)$ & $44(100)$ \\
3 & $6(15)$ & $33(85)$ & $39(100)$ \\
Total & 75 & 75 & 150 \\
\hline
\end{tabular}

Table 3 Patients with vitreous 'loss' related to grade and type of anaesthesia

\begin{tabular}{lllc}
\hline $\begin{array}{l}\text { Grade of } \\
\text { anaesthesia }\end{array}$ & $\begin{array}{l}\text { Without } \\
\text { hyaluronidase }\end{array}$ & $\begin{array}{l}\text { With } \\
\text { hyaluronidase }\end{array}$ & Total \\
\hline Grade 1 & 0 & 1 & 1 \\
Grade 2 & 1 & 0 & 1 \\
Grade 3 & 4 & 1 & 5 \\
Total & 5 & 2 & 7 \\
\hline
\end{tabular}

were more or less equally divided between the two groups (Table 2).

\section{COMPLICATIONS}

Seven patients $(4.6 \%)$ had prolapse of vitreous into the anterior chamber at the time of surgery. Five of those were in patients not given hyaluronidase and two in those who had added hyaluronidase. The difference is not statistically significant $(0 \cdot 2<\mathrm{p}<0 \cdot 5)$ (Table 3).

A larger series might show a difference, since it is my experience that vitreous prolapse is nearly always associated either with poor anaesthesia or with repeated retrobulbar injections. Repeated injections of fluid into the retrobulbar space will increase the pressure behind the eye in a manner analagous to that of a small retrobulbar haemorrhage. When the eye is opened and the intraocular pressure falls to zero, the effect of increased pressure behind the eye will be to push forward the vitreous in response to the pressure gradient created.

Twenty-one (14\%) patients had accidental rupture of the anterior lens capsule necessitating extracapsular lens extraction. Of those, $11(52 \cdot 4 \%)$ were in patients without added hyaluronidase and 10 $(47 \cdot 6 \%)$ were in the group with hyaluronidase. The difference is not statistically significant. 


\section{Discussion}

Hyaluronidase has been used as an adjunct to local anaesthesia since the late 1940s. It found favour with ophthalmologists and continues to do so (Christy NE, personal communication) despite Mindel's negative report in $1978 .{ }^{4}$ In his 27 cases there was a $25 \%$ failure rate without hyaluronidase and a $50 \%$ failure rate with hyaluronidase. Mindel, however, did not add adrenaline to his anaesthetic, so his results are what one might have predicted. Without adrenaline to restrict absorption the hyaluronidase acted only to increase diffusion, so limiting its effectiveness. He did find that the induction of anaesthesia was faster with hyaluronidase, which would be expected from the more rapid initial spread of the anaesthetic produced by the hyaluronidase.

Good local anaesthesia in cataract surgery is almost a sine qua non for good results. To operate on an eye which has perfect akinesia and anaesthesia is a relatively simple procedure, with a few complications and an excellent prognosis. To operate on an incompletely anaesthetised eye is an invitation to disaster.

Some practitioners are doubtless more adept than others at placing their retrobulbar injections exactly within the muscle cone. Oji and $\mathrm{Oji}$ got $73 \%$ absolute akinesia with lignocaine alone in their series of 30 patients and $93 \%$ of 30 patients with a mixture of lignocaine and bupivacaine. ${ }^{7}$ For those of us less skilled the addition of hyaluronidase probably allows for an error of $1 \mathrm{~cm}$ in the placement of the anaesthetic. $^{6}$

\section{CONCLUSION}

I recommend the addition of $15 \mathrm{IU}$ hyaluronidase $/ \mathrm{ml}$ to $2 \%$ lignocaine with adrenaline $1 / 100000$ for retrobulbar blocks as an aid to achieving complete ocular akinesia and anaesthesia in cataract surgery.

I am grateful to Mrs Joanna Thomson for recording the results and to the Zimbabwe Council for the Blind, Christoffel Blindenmission, and the Royal Commonwealth Society for the Blind, who provide the financial support for Norton Eye Unit.

\section{References}

1 Duthie ES, Chain EA. A mucolytic enzyme in testis extract. Nature 1939; 144: 977.

2 Atkinson WS. Use of hyaluronidase with local anesthesia in ophthalmology. Arch Ophthalmol 1949; 42: 628-33.

3 Lebensohn JE. Hyaluronidase in ocular surgery and therapy. Am J Ophthalmol 1950; 33: 865-70.

4 Mindel JS. Value of hyaluronidase in ocular surgical akinesia. Am J Ophthalmol 1978; 85: 643-6.

5 Vaughan AB. Anaesthetics. London: Oxford University Press, 1969: 217.

6 Kirby CK, Eckenhoff JE, Looby JP. The use of hyaluronidase with local anaesthetic agents in nerve block and infiltration anesthesia. Surgery 1949; 25: 101.

7 Oji E, Oji A. Bupivacaine and lignocaine for ophthalmic surgery Br J Ophthalmol 1987; 71: 66-8.

Accepted for publication 26 June 1987. 